\title{
BMJ Open Difference in the characteristics of mortality reports during a heatwave period: retrospective analysis comparing deaths during a heatwave in January 2014 with the same period a year earlier
}

Tony Pham, ${ }^{1}$ Caitlin Young, ${ }^{1}$ Noel Woodford, ${ }^{2}$ David Ranson, ${ }^{2}$ Carmel M F Young, ${ }^{1}$ Joseph E Ibrahim ${ }^{1}$

To cite: Pham T, Young C, Woodford N, et al. Difference in the characteristics of mortality reports during a heatwave period: retrospective analysis comparing deaths during a heatwave in January 2014 with the same period a year earlier. BMJ Open 2019;9:e026118. doi:10.1136/ bmjopen-2018-026118

- Prepublication history for this paper is available online. To view these files, please visit the journal online (http://dx.doi org/10.1136/bmjopen-2018026118).

Received 17 August 2018 Revised 26 February 2019 Accepted 10 April 2019
Check for updates

(c) Author(s) (or their employer(s)) 2019. Re-use permitted under CC BY-NC. No commercial re-use. See rights and permissions. Published by BMJ.

${ }^{1}$ Department of Forensic Medicine, Monash University, Southbank, Victoria, Australia

${ }^{2}$ Victorian Institute of Forensic Medicine, Southbank, Victoria, Australia

Correspondence to Dr Joseph E Ibrahim; joseph.ibrahim@monash.edu

\section{ABSTRACT}

Objectives To describe the characteristics of deaths reported to the Coroners Court of Victoria (CCOV) during Victoria's last heatwave (14-17 January 2014) and subsequent 4 days (18-21 January) using medicolegal data obtained from both the police investigation report and the pathologist's report.

Design, setting and participants A single-jurisdiction population-based retrospective analysis of consecutive heat-related deaths (HRDs) reported to the CCOV between 14 and 21 January 2014 with a historical comparison group.

Main outcome measures Descriptive statistics were used to summarise case demographics, causes of death and the types of investigations performed. The cases from 2014 were subgrouped into HRD and non-HRD.

Results Of the 222 cases during the study period in 2014 , 94 (42.3\%) were HRDs and 128 (57.7\%) were non-HRDs. HRDs were significantly older than non-HRDs (70.5 years: $\mathrm{SD}=13.8$ vs 61.0 years: $\mathrm{SD}=22.4, \mathrm{t}(220)=3.60, \mathrm{p}<0.001$, $95 \% \mathrm{Cl} 4.3$ to 14.6). The most common primary cause of death in HRDs was circulatory system disease $(n=57$, $60.6 \%$ ), which was significantly higher when compared with non-HRDs $\left(n=39,30.5 \% ; \chi^{2}=20.1, p<0.001\right.$, OR 3.5 , $95 \% \mathrm{Cl} 2.0$ to 6.2). HRDs required significantly greater toxicology investigation $(89.4 \%(n=84)$ vs $71.9 \%(n=92)$; $\chi^{2}=10.9, p<0.001$, OR $3.3,95 \% \mathrm{Cl} 1.54$ to 7.03 ) and greater vitreous biochemistry testing $(40.4 \%(n=38)$ vs $16.4 \%(n=21) ; \chi^{2}=16.0, p<0.001,0 R 3.5,95 \%$ Cl 1.9 to $6.5)$.

Conclusions A heatwave places a significant burden on death investigation services. The inclusion of additional laboratory tests and more detailed circumstantial information are essential if the factors that contribute to HRDs are to be identified.

\section{INTRODUCTION}

Heatwaves are defined by the Australian Bureau of Meteorology as 'a period of at least 3 days where the combined effects of excess heat and heat stress is unusual with respect to the local climate'. ${ }^{1}$ Among natural hazards
Strengths and limitations of this study

- Heat-related deaths (HRDs) were identified using medicolegal data obtained from both the police investigation report and the forensic pathologist's report, which are currently the best available data.

- A historical comparison group from 2013 (where there was no heatwave) was used in order to highlight the differences in the mortality reports from the 2014 heatwave.

- This is only the second study in Australia to use coronial data to examine the effects of heatwaves on mortality.

- This study provides data on resource use for investigation of HRDs, which could be used for planning for future heatwave events.

- Bias through exposure misclassification could be introduced as there is a well-recognised difficulty in the diagnosis and classification of HRDs, which has the potential to result in differences in individual forensic pathologist practice.

in Australia ${ }^{2}$ and the USA, ${ }^{3}$ heatwaves are the largest contributor to mortality. Heatwaves in Australia are occurring with greater frequency and intensity due to the effects of climate change. ${ }^{4}$ The elderly are vulnerable to the effects of heat, and as Australia's population is ageing, the number of people subject to heat-related morbidity and mortality will increase.

The 2009 and 2014 heatwaves in Victoria were responsible for an estimated 374 and 167 excess deaths, respectively. ${ }^{5}$ In particular, over the 4 days (14-17 January) of the 2014 heatwave, maximum temperatures of $42.8,41.7,43.9$ and $43.9^{\circ} \mathrm{C}$ were recorded, significantly higher than both the average maximum temperature of $26.0^{\circ} \mathrm{C}^{7}$ and the temperature threshold for ill health of $30.0^{\circ} \mathrm{C}^{8}$ This caused a $7 \%$ increase in 
emergency department presentations (1752 additional patient attendances) and a $23 \%$ increase in presentations of persons aged over 75 years (770 additional presentations). ${ }^{6}$ Excess heat morbidity and mortality pose operational and diagnostic challenges for both acute clinical services and coronial death investigation services. While the effects of this heatwave on hospital emergency department presentations and ambulance call-outs have been well documented, ${ }^{6}$ there is a paucity of data on the characteristics of the deaths caused by heatwaves.

Medicolegal death investigation plays an important role in ascertaining whether reportable deaths during a heatwave could be attributed to the effects of the excess heat. By using medicolegal data obtained from both the police investigation report and the pathologist's report in the medical aspects of the death investigation, we sought to describe the characteristics of deaths reported to the Coroners Court of Victoria (CCOV) during the January 2014 heatwave (14-17 January) and the subsequent 4 days (18-21 January).

\section{METHODS}

\section{Study design}

To describe the characteristics of deaths reported to the CCOV during Victoria's last heatwave (14-17 January 2014) and subsequent 4 days (18-21 January) using medicolegal data obtained from both the police investigation and the pathologist's report.

\section{Design, setting and participants}

The study design was a single-jurisdiction population-based retrospective analysis of consecutive heat-related deaths (HRDs) reported to the coroner with a historical comparison group.

\section{Setting}

The estimated population of Victoria in 2014 was 5817433. There were 38042 deaths in Victoria in 2014 and 35916 deaths in 2013. ${ }^{9}$

During the summer of 2014, Victoria experienced a heatwave with Melbourne, Victoria's capital city, recording maximum temperatures that exceeded $41^{\circ} \mathrm{C}$ for the 4 days from 14 to 17 January 2014 (42.8, 41.7, 43.9 and $43.9^{\circ} \mathrm{C}$, respectively). ${ }^{10}$ For Victoria, this 4 -day period represented the highest average maximum temperature $\left(41.7^{\circ} \mathrm{C}\right)$, the third highest average minimum temperature $\left(21.8^{\circ} \mathrm{C}\right)$ and the highest average mean temperature $\left(31.8^{\circ} \mathrm{C}\right)$, since records commenced in $1911 .^{10}$

Deaths reported to the coroner on 14-21 January 2014 (ie, the 4-day heatwave period (14-17 January) and the subsequent 4 days (18-21 January)) were examined. The historical comparison group was taken from the same dates in 2013 (14-21 January) in order to examine the effect of the heatwave on the forensic pathology service as a whole (cases reported and investigations carried out).

\section{Cases}

In Victoria, deaths must be reported to the coroner if (1) the deceased was in the care of the state, in custody or an involuntary mental health patient; (2) the death was unexpected, unnatural and violent (including an accident or injury); (3) the identity of the deceased is unknown; (4) the cause of the death is unknown or (5) the death occurred unexpectedly during or following a medical procedure. ${ }^{11}$ Heatwave-related deaths are generally considered in either the second or fourth of these categories.

When a reportable death occurs, the police or the responsible medical practitioner notifies the coroner. Forensic pathologists at the Victorian Institute of Forensic Medicine (VIFM) investigate the medical aspects of the death and provide a report to the coroner regarding the cause of death and relevant medical factors. Investigation of such deaths usually involves a full body CT scan, a review of any available medical records, the police report as to the circumstances surrounding the death, an external examination of the body and, if required, further laboratory testing, including toxicology, vitreous biochemistry and microbiology. Most investigations comprise either autopsies, where the body cavity is opened and a formal pathological examination of the internal organs is performed, or a more limited examination where, in addition to the examination of the medical records, an external examination of the body occurs with associated laboratory testing but no internal dissection (referred to as 'an external inspection').

All deaths reported to the coroner during the study periods underwent investigation.

\section{Variables}

Data collected from the VIFM case management system included demographics (date of birth and sex) and details of the forensic investigation (date of report, investigation type, cause of death and investigations undertaken). The data were extracted by one person (CMFY) with a standard abstraction form and were checked by another (CY) for accuracy.

As reports of cause of death from the forensic pathologists are entered as a free-text statement, a National Coronial Information Services employee undertook International Classification of Diseases, 10th Revision (ICD-10) death coding of all cases from 2014 in order to better characterise the causes of death. The ICD-10 coding process included coding of all diseases, symptoms and conditions documented in the forensic pathology report with subsequent ranking in order of their contribution to the death.

Charlson Comorbidity Index (CCI) scores were assigned to the cases according to a validated ICD-10 coding algorithm. ${ }^{12}$ Cases were separated into three categories based on their CCI scores: none (0), mild (1-2), and moderate or severe $(\geq 3)$.

Cases from 2014 were subgrouped by the research team into HRDs and non-HRDs (see table 1 for definitions). Where there was discordance in this classification, two expert forensic pathologists (DR and NW) were consulted to interpret the forensic pathology report. There were 
Table 1 Definitions of case classification

Heat-related death There was the ICD-10 code X30 (exposure to excessive natural heat) or T67 (effects of heat and light) in the cause of death coding or either the forensic pathologist or police report included terms such as 'heat' or 'heatwave' or 'heat-related' or 'high temperature' or 'high ambient temperature'.

$\begin{array}{ll}\begin{array}{l}\text { Non-heat-related } \\ \text { death }\end{array} & \text { X30 or T67 code not included in the } \\ & \text { cause of death coding, and neither the } \\ & \text { forensic pathology nor the police report } \\ \text { identifies heat as a contributing factor in } \\ \text { the case. }\end{array}$

ICD-10, International Classification of Diseases, 10th Revision.

no HRDs in 2013 (average daily maximum temperature $\left.26.9^{\circ} \mathrm{C}\right)$. $^{13}$

\section{Statistical analysis}

Data were analysed using SPSS V.20. ${ }^{14}$ Descriptive statistics were used to summarise case demographics, causes of death and the types of investigations performed.

Sex was compared between cases using a $\chi^{2}$ test. Mean age (calculated between the date of birth and the date of report) was compared between groups using an independent samples t-test. Median age was also calculated to compare with data from the Australian Bureau of Statistics - the median age of overall deaths in Victoria. Deaths from 2014 and 2013 were divided into age groups of 5 years $(0-4,5-9, \ldots, 90-94,>95)$, and the frequencies were subsequently compared using age-standardised mortality rates. This was computed to highlight the likelihood of cases from specific age groups being reported to the coroner.

For cases from 2014, ICD-10 coding and CCI scores were used to examine the cause of death. The primary cause of death was classified according to the chapter of the first ICD-10 code (eg, Chapter IX-Diseases of the circulatory system). Particular conditions, signified by specific ICD-10 codes (eg, ischaemic heart disease I20-25), were deemed to have contributed to the death if the code was found anywhere in the ICD-10 coding. $\chi^{2}$ tests were used to compare the prevalence of the conditions between subgroups, and ORs were calculated to quantify the differences. CCI scores were compared between subgroups using an independent samples t-test.

The type of investigation undertaken (autopsy or external inspection) and further investigations performed (toxicology, vitreous biochemistry and microbiologycases from 2014 only) were compared using $\chi^{2}$ tests, and ORs were calculated to quantify these differences.

\section{Patient and public involvement}

The public were not involved in the development and design of this study.

\section{RESULTS \\ Cases}

Overall, 255 deaths were identified during the study period in 2014, of which 222 cases, where a cause of death had been established, were included in the analysis. During the comparison period in 2013, 97 deaths were identified, and 74 cases were included in the analysis (figure 1).
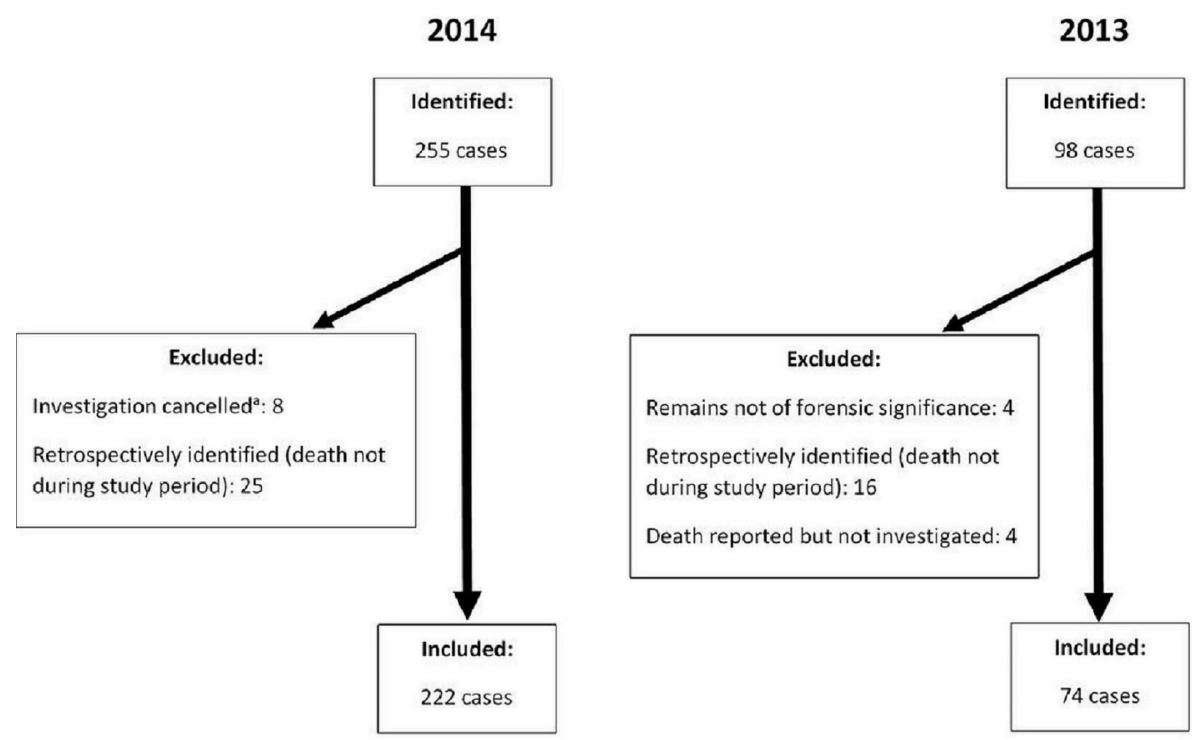

${ }^{a}$ Death initially reported but investigation was not required as the death was certified by a community practitioner

Figure 1 Selection and screening of cases reported to the Coroners Court of Victoria and investigated by pathologists from the Victorian Institute of Forensic Medicine during 14-21 January 2014 and 2013. 


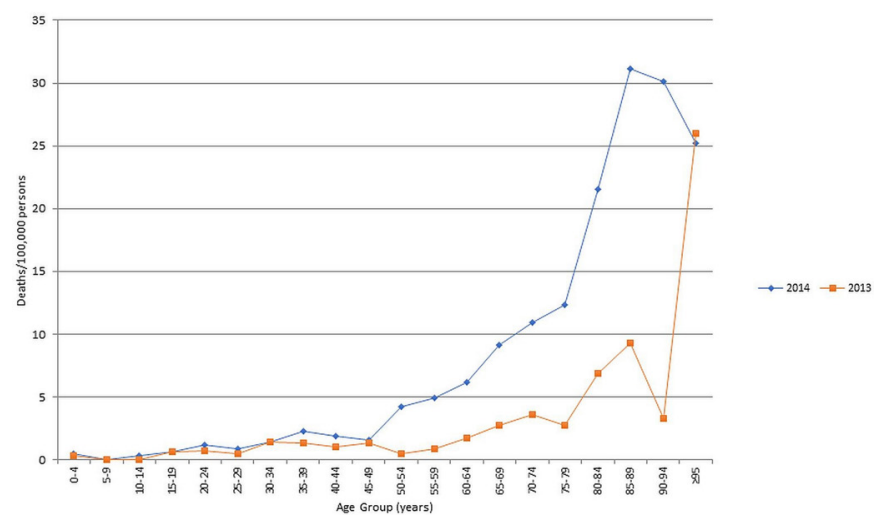

Figure 2 Age-standardised rates of deaths of cases from $2014(n=222)$ and $2013(n=74)$.

\section{Descriptive statistics}

In the 2014 study period, almost two-thirds of all cases $(\mathrm{n}=143,64.4 \%)$ were men. This was not significantly different from the same period in $2013(n=44,59.5 \%)$ but was higher than the deaths in the general Victorian population in 2014, of which men comprised $50.4 \%$ $(\mathrm{n}=19190) .^{15}$

In the state of Victoria, the median age of death was 82.3 years in 2014 and 82.2 years in 2013. In the study population, the median age of death was 67.4 years in 2014 and 64.4 years in 2013-a difference of 14.9 and 17.8 years, respectively.

In the 2014 heatwave period, the rate of deaths per 100000 of the population by age category was substantially higher in those aged between 50 and 94 years, compared with the average rate of deaths over the same period in January 2013 (figure 2). Furthermore, the mean age of cases from 2014 was significantly higher than that of the cases from 2013 (65.0 years: SD=19.8 vs 59.4 years: $\mathrm{SD}=23.0, \mathrm{t}(294)=2.05, \mathrm{p}=0.042,95 \%$ CI 0.2 to 11.1$)$. There were no differences in the sex distribution between 2014 and 2013 cases.

Of the 222 deaths during the 2014 study period, 94 $(42.3 \%)$ were HRDs and $128(57.7 \%)$ were non-HRDs.

The mean age of HRDs was 70.5 years $(\mathrm{SD}=13.8)$, which was significantly higher than that of non-HRDs $(61.0$ years: $\mathrm{SD}=22.4, \mathrm{t}(220)=3.60, \mathrm{p}<0.001,95 \%$ CI 4.3 to 14.6$)$. There were no significant differences in sex between the two groups (table 2).

\section{Deaths over the heatwave period}

During the first 3 days of the heatwave, there was an increase in the number of HRDs each day (figure 3). HRDs peaked at 38 deaths on the final day of the heatwave (17 January). HRDs then decreased over the next 4 days with three on the final day of the study period (21 January). The number of non-HRDs ranged from 11 to 23 deaths per day over the study period and appeared to not be proportional to the maximum temperature.

The distribution of reported deaths during the study period (range: 14-52 deaths per day) is in contrast to the relatively stable distribution of reported deaths in the comparison period in 2013 (range: 6-14 deaths per day) (figure 3).

\section{Cause of death}

Comparisons between the causes of death of the 2014 subgroups are summarised in table 2. The most common primary cause of death in HRDs was circulatory system disease $(n=57,60.6 \%)$, which was significantly higher when compared with non-HRDs $\left(n=39,30.5 \% ; \chi^{2}=20.1\right.$, $\mathrm{p}<0.001$, OR 3.5, 95\% CI 2.0 to 6.2 ).

In non-HRDs, the most common primary cause of death was 'injury, poisoning and other consequences of external causes' $(n=56,43.8 \%)$. This was significantly higher when compared with HRDs $\left(n=5,5.3 \% ; \chi^{2}=40.1\right.$, $\mathrm{p}<0.001$, OR $0.07,95 \%$ CI 0.03 to 0.19 ).

The following conditions contributing to death were observed to significantly occur more frequently in HRDs than in non-HRDs: ischaemic heart disease $(n=58(61.7 \%)$ vs $\mathrm{n}=45(35.2 \%), \chi^{2}=15.4, \mathrm{p}<0.001$, OR $3.0,95 \%$ CI 1.7 to $5.2)$, chronic lower respiratory disease $(n=19(20.2 \%)$ vs $\mathrm{n}=8(6.3 \%), \chi^{2}=9.9, \mathrm{p}=0.002$, OR $3.8,95 \%$ CI 1.6 to 9.1$)$, and mental and behavioural disorders $(n=27(28.7 \%)$ vs $\mathrm{n}=21(16.4 \%), \chi^{2}=4.9, \mathrm{p}=0.028$, OR $2.1,95 \%$ CI 1.1 to $3.9)$.

The mean CCI score was not significantly different between HRDs and non-HRDs $(\mathrm{t}(220)=1.77, \mathrm{p}=0.78)$. There were also no significant differences in the number of cases in the none, mild and moderate or severe categories between the subgroups $\left(\chi^{2}=3.1, \mathrm{p}=0.21\right)$.

\section{Investigation of deaths}

Of the cases reported during the 2014 study period, 100 cases (45.0\%) underwent an autopsy and 122 had an external inspection only $(55.0 \%)$. This was not significantly different when compared with the 2013 cases, with 27 autopsies $\left(36.5 \%\right.$, OR $1.4, \chi^{2}=1.7, p=0.20,95 \%$ CI 0.8 to 2.5$)$ and 47 external inspections (63.5\%).

Comparisons of death investigations between subgroups are summarised in table 2 . With respect to the 2014 cases, there was no significant difference in the proportion of HRDs and non-HRDs that underwent autopsies $(n=22$ $(40.7 \%)$ vs $\mathrm{n}=51$ (39.8\%), respectively; $\chi^{2}=1.6, \mathrm{p}=0.069$, OR $1.6,95 \%$ CI 0.96 to 2.81$)$.

However, HRDs required significantly greater toxicology investigation, with $89.4 \%(\mathrm{n}=84)$ undergoing toxicology analysis compared with $71.9 \%(n=92)$ of non-HRDs $\left(\chi^{2}=10.9, \mathrm{p}<0.001\right.$, OR $3.3,95 \%$ CI 1.54 to 7.03$)$. These cases also required significantly greater vitreous biochemistry testing $\left(\mathrm{n}=38(40.4 \%)\right.$ vs $\mathrm{n}=21 \quad(16.4 \%), \chi^{2}=16.0$, $\mathrm{p}<0.001$, OR $3.5,95 \%$ CI 1.9 to 6.5$)$. The number of cases in which microbiology was undertaken was very low, with no significant difference between subgroups.

\section{DISCUSSION}

This study identified that $94(42.3 \%)$ of the 222 deaths reported to the coroner during Victoria's 2014 heatwave and the subsequent 4 days were heat-related. This 
Table 2 Demographics and characteristics of 2014 subgroups $(n=222)$

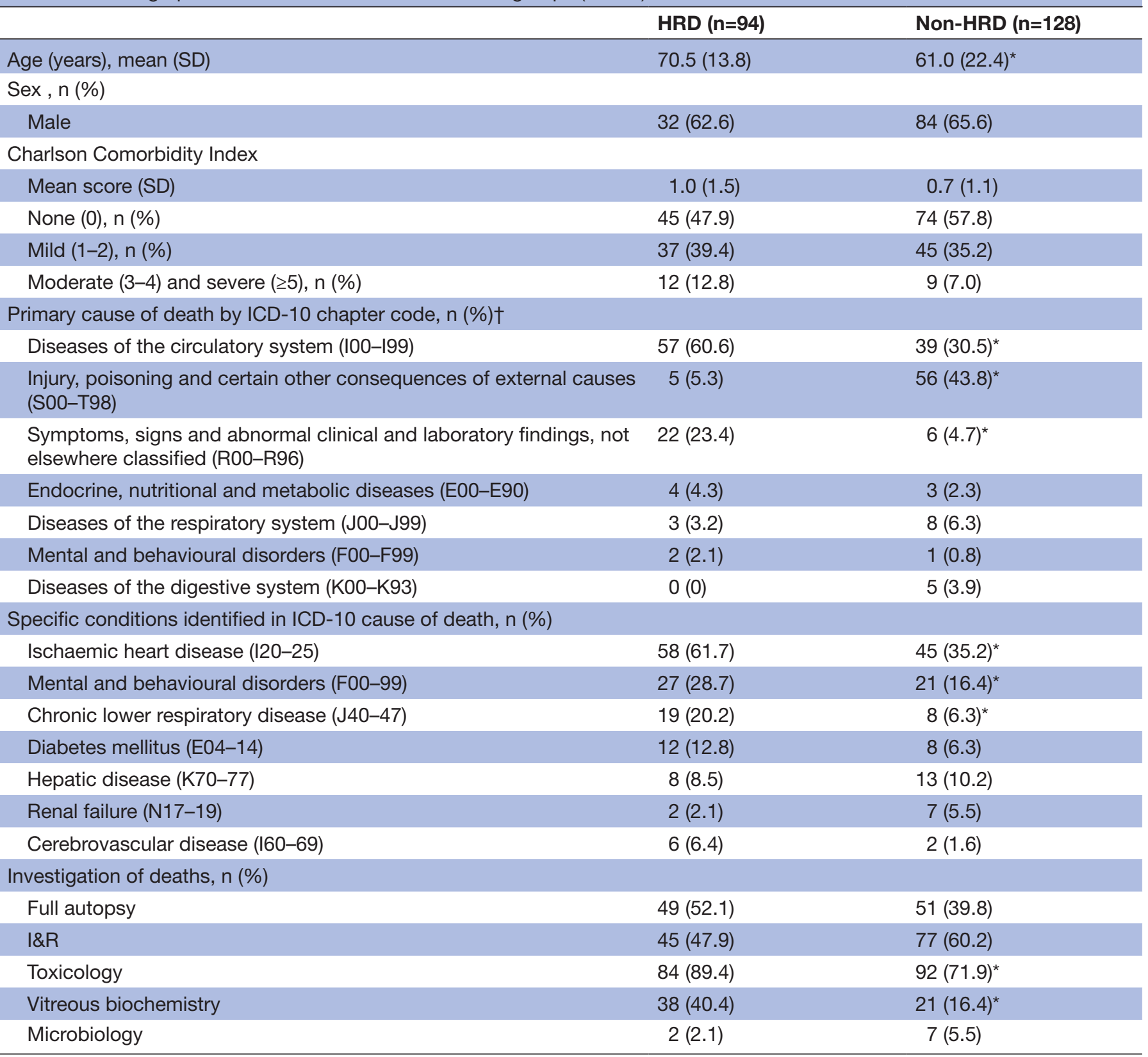

${ }^{*} \mathrm{P}<0.05$.

†Other primary causes not included in table due to low frequency of occurrence. HRD, heat-related death; I\&R, investigation and report.

ICD-10, International Classification of Diseases, 10th Revision.

is substantially less than the 167 excess deaths officially reported for this period. ${ }^{6}$ The HRDs in our study accounted for only $56.3 \%$ (94/167) of the excess deaths reported. The difference in excess deaths is due to this study recording only deaths reported to the coroner. The deaths not reported were likely misclassified. The reason for this is unclear, but it is likely that the death was considered to be due to natural causes, and the contribution of environmental (heat) factors was either not recognised or not thought to have made the death reportable.
When comparing the reported deaths in 2014 and 2013 from the same time period, there was no significant difference in sex; however, age was significantly higher in 2014 (mean age: 65.0 vs 59.4 years), and this was demonstrated by the age-standardised death rates, which were higher between the 50 and 94 age groups.

Similarly, cases reported to be due to heat-related causes (HRDs) were more likely to be older, and sex did not have any effect. The causes of death in HRDs were consistent with previous studies in the USA and across Europe that have reported a greater risk of death in 


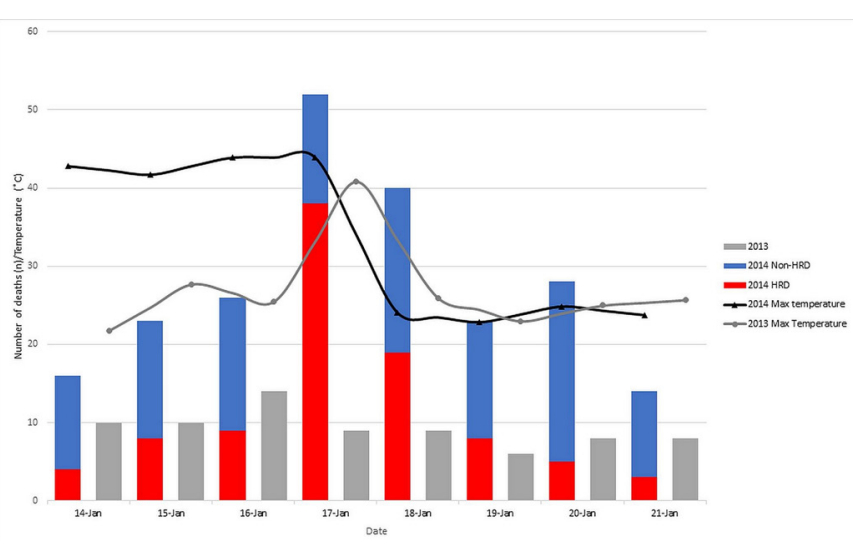

Figure 3 Number of reported deaths and temperature of each day during the period between 14 January and 21 January $2014(n=222)$ and $2013(n=74)$. HRD, heatrelated death.

older individuals, ${ }^{16}$ and those with cardiovascular disease, mental disorders and pulmonary disease. ${ }^{17-19}$

Individuals with chronic disease are recognised to be more likely to die during heatwaves. ${ }^{20}$ However, this was not demonstrated in our study of deaths reported to the coroner, as CCI scores for these cases were not significantly different between HRDs and non-HRDs.

This study identified that HRDs also underwent a greater range of medical and scientific investigations with more toxicology and vitreous biochemistry testing being requested by pathologists. This observation has important management considerations. It is recognised that emergency service agencies have to enact targeted plans $^{6}$ to ensure adequate service provision during the event of a heatwave. However, the understanding that forensic pathology services will require increased medical and scientific resources to adequately investigate deaths related to heatwaves is far less understood by health and justice agencies. The social, circumstantial and legal aspects of a death investigation are also significant in these cases, requiring that plans be in place to meet the increased legal or court-related workload that accompanies the investigation of deaths during heatwaves as well as other natural disasters. ${ }^{21}$

Over the 8-day study period, it was observed that most reported deaths occurred during 17 and 18 January. The pattern of HRDs was also consistent with this, with most HRDs being reported on 17 and 18 January. In comparison with 2013, when the distribution of deaths was fairly constant in number over the same period, the deaths in 2014 displayed a distribution consistent with the nature of heatwave deaths, that is, a sharp increase in deaths (usually within 2 days) with a return to baseline levels when the temperature normalises. ${ }^{22}{ }^{23}$ It was with the intention of capturing this trend that the study period included the first 4 days of the heatwave and the following 4 days.

There has been a paucity of research into heatwave deaths using coronial (or medical examiner) data. To the authors' knowledge, this is only the second study in Australia to use coronial data to examine the effects of heatwaves on mortality. The first study described the characteristics of deaths during the 2009 heatwave in Adelaide. ${ }^{24}$ This study found that there was no age or sex difference between HRDs and non-HRDs, and that most HRDs were due to either cardiac (59\%) and pulmonary $(6 \%)$ diseases or a combination of the two.

Other international studies using coronial data have originated largely from the USA. ${ }^{192526}$ A recent study by Johnson $e t a l^{19}$ used vital statistics and coronial data to identify HRDs between 1990 and 2011. They similarly looked at the ICD-10 coding of the deaths and the investigation narrative to ascertain which deaths were heat-related. Their results found that HRDs were highest in men, black people and those aged 65 years or over. It was also reported that cases with known cardiac disease $(47 \%$ of cases), psychiatric disorder (27\%) and pulmonary disease $(10 \%)$ were at greater risk of HRD. The present study reported similar results in terms of increased age being a risk factor and the comorbidities associated with HRDs-cardiac disease, namely, ischaemic heart disease $(61.7 \%)$; psychiatric disorder $(28.7 \%)$ and pulmonary disease $(20.2 \%)$. However, our study did not find an increased risk of death in men, and data on race were not extracted.

\section{Limitations}

There is well-recognised difficulty in medically identifying HRDs due to a lack of specific macroscopic and microscopic findings. ${ }^{19} 27$ This has the potential to result in differences in reporting practices where death investigations are performed by different forensic pathologists. This could lead to exposure misclassification, where inconsistencies are seen in the application of the definition of an HRD leading to the size and characteristics of HRDs being misrepresented.

This study was retrospective and relied on the quality of data recorded in the coroner's files. The recorded operational data were obtained from a wide range of police officers and medical practitioners and contained variable amounts of information regarding the environmental and social aspects of the circumstances surrounding the death. The study used a historical comparison group from 2013 in order to compare the number and a limited set of characteristics of cases that had been reported to the coroner. This was used with the knowledge that the forensic pathologists and procedures within VIFM had not changed between 2013 and 2014, thereby minimising any major variations in the classification of cases.

\section{Implications and future directions}

Following the aftermath of the 2014 heatwaves, a heat health plan was developed for the state of Victoria in $2015 .^{28}$ This plan sought to raise awareness about the adverse effect of excess heat and to describe how information should be disseminated to the public, especially vulnerable populations (elderly, persons with chronic disease and, anyone who is socially isolated) and their carers. More specifically, the plan outlined the particular 
actions required of certain organisations (police and health services) and levels of government (state and local) at specific time points (before, during and after a heatwave) in order to prevent adverse health outcomes.

\section{CONCLUSION}

HRDs pose a range of medicolegal as well as public health problems. We found that the 2014 Victorian heatwave increased the rate of death of those over the age of 50 and that the most common causes of death were diseases of the circulatory system, chronic lower respiratory disease, and mental and behavioural disorders. While a heatwave will place an increased burden on health services, its effects on coroners or medical examiner death investigation services are also significant. Excess deaths due to heat-related factors not only reduce forensic and public mortuary storage capacity but also have a significant community impact regarding bereavement and funeral service capacity. For the forensic medical death investigator, the potentially increased investigative processes these deaths demand are costly; however, the definitional and practical problem of identifying HRDs means that the inclusion of additional laboratory tests and more detailed circumstantial investigations is essential if the factors that can contribute to these deaths are to be identified and ultimately prevented.

Contributors Study concept and design: CY, NW, DR and JEI. Data analysis and collection: TP, CY, NW, DR and CMFY. Drafting of the manuscript: TP and CY. Critical revision of the manuscript: TP, CY, NW, DR, CMFY and JEI.

Funding The authors have not declared a specific grant for this research from any funding agency in the public, commercial or not-for-profit sectors.

Competing interests None declared.

Patient consent for publication Not required.

Ethics approval The Victorian Institute of Forensic Medicine ethics committee provided ethical approval for this study (approval number: RAC 001/14).

Provenance and peer review Not commissioned; externally peer reviewed.

Data sharing statement Data cannot be shared publicly because of confidentiality and privacy issues. Data may be available with a formal application to the institutional ethics committee (contact via http://www.vifm.org/our-services/ academic-programs/research/) for researchers who meet the criteria for access to confidential data.

Open access This is an open access article distributed in accordance with the Creative Commons Attribution Non Commercial (CC BY-NC 4.0) license, which permits others to distribute, remix, adapt, build upon this work non-commercially, and license their derivative works on different terms, provided the original work is properly cited, appropriate credit is given, any changes made indicated, and the use is non-commercial. See: http://creativecommons.org/licenses/by-nc/4.0/.

\section{REFERENCES}

1. Nairn J, Fawcett R. Defining Heatwaves: heatwave defined as a heat-impact even servicing all community and business sectors in Australia: CSIRO and Australian Bureau of Meteorology, 2013.

2. Coates L, Haynes K, O'Brien J, et al. Exploring 167 years of vulnerability: An examination of extreme heat events in Australia 1844-2010. Environ Sci Policy 2014;42:33-44.

3. Centers for Disease Control and Prevention (CDC). Heat-related deaths after an extreme heat event--four states, 2012, and United States, 1999-2009. MMWR Morb Mortal Wkly Rep 2013;62:433-6.
4. Steffen W, Hughes L, Perkins S. Heatwaves: Hotter, Longer, More Often: Climate Council of Australia, 2014

5. Bureau of Meteorology. SPECIAL CLIMATE STATEMENT 17 The exceptional January-February 2009 heatwave in south-eastern Australia, 2009.

6. Department of Health. The health impacts of the January 2014 heatwave in Victoria. Melbourne: State Government of Victoria, 2014.

7. Bureau of Meteorology. Climate statistics for Australian locations. Bureau of Meteorology. 2019 http://www.bom.gov.au/climate/ averages/tables/cw_086071.shtml (17 Feb 2019).

8. Services DoHH. Heat health alerts 2018. https://www2.health.vic. gov.au/public-health/environmental-health/climate-weather-andpublic-health/heatwaves-and-extreme-heat/heat-health-alerts (17 Feb 1019).

9. Australian Bureau of Statistics (ABS). Life Expectancy and Deaths Hit Historic Highs. Australian Bureau of Statistics (ABS). $2015 \mathrm{http} / / /$ www.abs.gov.au/ausstats\%5Cabs@.nsf/mediareleasesbyCatalogue/ F95E5F868D7CCA48CA25750B0016B8D8?Opendocument (3 Dec 2017).

10. Bureau of Meteorology. Special Climate Statement 48 - one of southeast Australia's most significant heatwaves: Bureau of Meteorology, 2014.

11. VIC [statute on the Internet]. Coroners Act 2008. 2008 www. legislation.vic.gov.au/Domino/Web_Notes/LDMS/PubStatbook.nsf/ f932b66241ecf1b7ca256e92000e23be/A03B804587FBF657CA25 751C00212DA0/\$FILE/08-077a.pdf (4 Dec 2017).

12. Quan H, Sundararajan V, Halfon P, et al. Coding algorithms for defining comorbidities in ICD-9-CM and ICD-10 administrative data. Med Care 2005;43:1130-9.

13. Bureau of Meteorology. Daily maximum temperature, Melbourne Regional Office. Bureau of Meteorology. 2017 www.bom.gov.au/jsp/ ncc/cdio/weatherData/av?p_pnccObsCode $=122 \& p \_d i s p l a y \_t y p e=$ dailyDataFile\&p startYear=2013\&p c=-1481843664\&p_stn num= 086071 (6 Dec 2017).

14. IBM Corp. IBM SPSS Statistics for Windows. Armonk, NY: IBM Corp, 2011.

15. Australian Bureau of Statistics (ABS). 3101.0 Australian Demographic Statistics. TABLE 4. Estimated Resident Population, States and Territories (Number): Australian Bureau of Statistics (ABS), 2014.

16. Pirard $\mathrm{P}$, Vandentorren $\mathrm{S}$, Pascal $\mathrm{M}$, et al. Summary of the mortality impact assessment of the 2003 heat wave in France. Euro Surveill 2005;10:7-8.

17. Fouillet A, Rey G, Laurent F, et al. Excess mortality related to the August 2003 heat wave in France. Int Arch Occup Environ Health 2006;80:16-24.

18. Centers for Disease Control and Prevention (CDC). Heat-related illnesses, deaths, and risk factors--Cincinnati and Dayton, Ohio, 1999, and United States, 1979-1997. MMWR Morb Mortal Wkly Rep 2000;49:470-3.

19. Johnson MG, Brown S, Archer P, et al. Identifying heat-related deaths by using medical examiner and vital statistics data: Surveillance analysis and descriptive epidemiology - Oklahoma, 1990-2011. Environ Res 2016;150:30-7.

20. Foroni M, Salvioli G, Rielli R, et al. A retrospective study on heatrelated mortality in an elderly population during the 2003 heat wave in Modena, Italy: the Argento Project. J Gerontol A Biol Sci Med Sci 2007;62:647-51.

21. Cordner SM, Woodford N, Bassed R. Forensic aspects of the 2009 Victorian Bushfires Disaster. Forensic Sci Int 2011;205:2-7.

22. Michelozzi P, de Donato F, Bisanti L, et al. The impact of the summer 2003 heat waves on mortality in four Italian cities. Euro Surveill 2005;10:11-12

23. Cheng J, Xu Z, Bambrick $\mathrm{H}$, et al. Heatwave and elderly mortality: an evaluation of death burden and health costs considering short-term mortality displacement. Environ Int 2018;115:334-42.

24. Herbst J, Mason K, Byard RW, et al. Heat-related deaths in Adelaide, South Australia: review of the literature and case findings - an Australian perspective. J Forensic Leg Med 2014;22:73-8.

25. Ostro BD, Roth LA, Green RS, et al. Estimating the mortality effect of the July 2006 California heat wave. Environ Res 2009;109:614-9.

26. Christenson ML, Geiger SD, Anderson HA. Heat-related fatalities in Wisconsin during the summer of 2012. WMJ 2013;112:219-23.

27. Nixdorf-Miller A, Hunsaker DM, Hunsaker JC. Hypothermia and hyperthermia medicolegal investigation of morbidity and mortality from exposure to environmental temperature extremes. Arch Pathol Lab Med 2006;130:1297-304.

28. Department of Health \& Human Services. Heat health plan for Victoria. Melbourne: Victorian Government, 2015. 